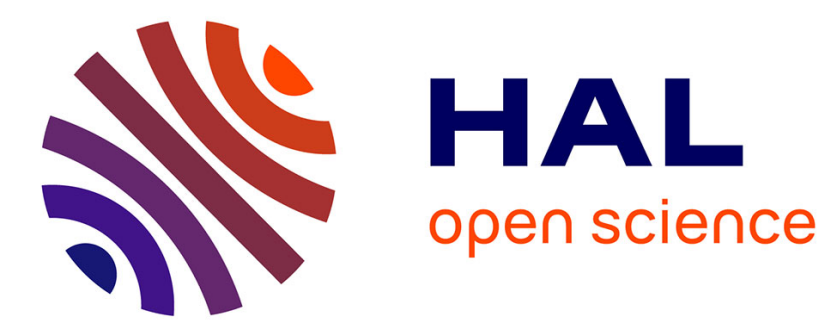

\title{
Unravelling the Impact of Calcium Content on the Bioactivity of Sol-Gel-Derived Bioactive Glass Nanoparticles
}

Xavier Kesse, C. Vichery, Aurelie Jacobs, Stéphane Descamps, Jean-Marie Nedelec

\section{To cite this version:}

Xavier Kesse, C. Vichery, Aurelie Jacobs, Stéphane Descamps, Jean-Marie Nedelec. Unravelling the Impact of Calcium Content on the Bioactivity of Sol-Gel-Derived Bioactive Glass Nanoparticles. ACS Applied Bio Materials, 2020, 3 (2), pp.1312-1320. 10.1021/acsabm.0c00036 . hal-03008293

\section{HAL Id: hal-03008293 \\ https://hal.uca.fr/hal-03008293}

Submitted on 16 Nov 2020

HAL is a multi-disciplinary open access archive for the deposit and dissemination of scientific research documents, whether they are published or not. The documents may come from teaching and research institutions in France or abroad, or from public or private research centers.
L'archive ouverte pluridisciplinaire HAL, est destinée au dépôt et à la diffusion de documents scientifiques de niveau recherche, publiés ou non, émanant des établissements d'enseignement et de recherche français ou étrangers, des laboratoires publics ou privés.

$$
\text { Copyright }
$$




\title{
Unravelling the impact of calcium content on the bioactivity of sol-gel derived bioactive glass nanoparticles
}

Xavier Kesse, Charlotte Vichery*, Aurelie Jacobs, Stéphane Descamps, Jean-Marie Nedelec. Université Clermont Auvergne, CNRS, SIGMA Clermont, ICCF, F-63000 Clermont-Ferrand,

France.

\begin{abstract}
Sol-gel derived bioactive glass nanoparticles (BGNs) are fascinating materials for bone regeneration. In the literature, it can be found that their specific surface area and their calcium content $(\mathrm{Ca} / \mathrm{Si}$ ratio) are the two key parameters impacting strongly the particles bioactivity. Nevertheless, in most studies, in vitro bioactivity tests are performed on series of materials where both the composition and the specific surface area are varied. It is thus difficult to unravel the effect of each parameter independently. In this study, spherical and monodispersed BGNs with different $\mathrm{Ca} / \mathrm{Si}$ ratio and similar specific surface area have been synthesized by a modified Stöber method in order to specify the impact of the calcium content only. The mineralization studies performed in simulated body fluid showed that the bioactivity increases with the amount of calcium incorporated in the glass matrix. However, this effect is not significant in the composition interval studied $(7-15 \% \mathrm{~mol}$ of $\mathrm{CaO})$. Such a result proves that the effective $\mathrm{Ca} / \mathrm{Si}$ ratio is not the major parameter which affects the bioactivity of sol-gel binary BGs. In vitro biocompatibility assessment during 3 and 7 days using human Mesenchymal Stem Cells in contact with the sample showing the fastest mineralization proved its non-cytotoxicity. Hence, biomedical applications can be intended for this sample.
\end{abstract}

KEYWORDS: Bioactive glass, nanoparticles, sol-gel, bioactivity, composition. 


\section{INTRODUCTION}

Bioactive implants are promising materials for medical applications especially for bone tissue engineering. ${ }^{1}$ Their bioactivity is characterized by the formation of an hydroxyapatite layer (HAp) on their surface whereby a strong interfacial bond is established with the surrounding tissues. ${ }^{2}$ Among those materials, bioactive glasses (BGs) exhibit osteoconductive and possible osteoinductive properties ${ }^{3,4}$ which make them suitable materials for clinical applications in periodontology $y^{5,6}$, endodontology. ${ }^{7,8}$ or orthopaedics.

Nowadays, the most widely used techniques to elaborate BGs are the melt quenching process and the sol-gel route. In the conventional melt quenching method, the precursors are melted at high temperature (above $1000^{\circ} \mathrm{C}$ ) and casted in a graphite or steel mold to produce bulk implants which can then be grinded to obtain particles. ${ }^{9}$ This method allowed the elaboration of BGs in the $\mathrm{SiO}_{2}-\mathrm{Na}_{2} \mathrm{O}-\mathrm{CaO}-\mathrm{P}_{2} \mathrm{O}_{5}$ system with a $\mathrm{SiO}_{2}$ composition up to $60 \%$ mol. ${ }^{9}$ On the other hand, sol-gel is a wet chemistry route which involves the hydrolysis and condensation of alkoxyde precursors in an aqueous/alcoholic solution at room temperature leading to the formation of an inorganic network in acidic media or particles in basic media. This method is very versatile as the size, composition, morphology and textural properties of the particles can be precisely controlled by the process itself. ${ }^{10}$ Moreover, sol-gel based bioactive materials exhibit an enhanced bioactivity compared to the melted-produced ones ${ }^{9}$ and there is research evidence that BG particles with only two components $\left(\mathrm{SiO}_{2}-\mathrm{CaO}\right)$ can be synthesized by this process. ${ }^{11}$ In addition, it has been reported that glasses in this binary system with a $\mathrm{CaO}$ content down to 10 $\%$ mol still exhibit bioactive properties. ${ }^{12}$ Furthermore, a relevant benefit of this method is the low temperature process that also enables the formation of porous bioactive scaffolds and hybrid materials. ${ }^{13,14}$

Designing nanobiomaterials is highly relevant since the building block components (proteins, lipids, carbohydrates...) of biological tissues have nanoscale dimensions. ${ }^{15}$ In addition, nanobiomaterials are characterized by a high surface to volume ratio $(\mathrm{S} / \mathrm{V})$ and a large specific surface area which promote positive interactions with cells. ${ }^{15-17}$ In the case of bioactive glass nanoparticles (BGNs), Fan and coworkers showed that they enhanced osteoblast adhesion, proliferation and differentiation and promoted a rapid biomineralization process. ${ }^{18}$ Gong et al. ${ }^{19}$ also pointed out that the high specific surface area of nano-sized $58 \mathrm{~S}$ bioactive glass particles led to a better gene activation of osteoblast cells compared to micron-sized 45S5 bioglass particles. Another advantage of the BGNs is the mechanical strength improvement of bioactive composite scaffolds mimicking the mechanical properties of natural bones. ${ }^{20-22}$ It has also been reported that the smaller the particle size is, the faster the hydroxyapatite formation is ${ }^{23}$ Thus, decreasing the size of BG particles allows the control of their bioreactivity. Based on these results, a lot of research has been focused on the elaboration of BG nanoparticles. 
A common sol-gel procedure to synthesize BGNs is the modification of the so-called Stöber process. ${ }^{24}$ Indeed in a first step, monodispersed and discrete silica particles are obtained through the hydrolysis and condensation of a silicon alkoxyde (usually TEOS, tetraethoxysilane) in a strong basic environment. Such a high $\mathrm{pH}$ value, above the isoelectric point of silica (IEP = 2.2) induces a negative charge at the surface of silica particles. They thus tend to electrostatically repel each other. Then, a calcium precursor (often $\mathrm{Ca}\left(\mathrm{NO}_{3}\right)_{2}$ ) is added in the media and post synthetic treatments, namely particles washing, drying and annealing (above $400^{\circ} \mathrm{C}$ ) the particles, allow to impart the bioactive property. ${ }^{25}$

Since the discovery of the bone-bonding ability of bioactive glasses, numerous studies reported the impact of several parameters on the HAp formation speed, namely their bioactivity. Among them, it appeared that the bioactivity was greatly affected by the glass textural parameters and composition. The results of some research groups are presented in the Table 1. El-Rashidy et $a l .{ }^{26}$ showed in their work that a high calcium content and a high specific surface area of sol-gel derived bioactive glass particles led to their fast dissolution and a rapid ionic release in the immersion media (Simulated Body Fluid, SBF), factors promising an enhanced bioactivity. Similarly, Saravanapavan et al. ${ }^{11}$ reported that it is difficult to unravel the effect of the composition from the one of the textural features of $\mathrm{SiO}_{2}-\mathrm{CaO}$ particles on the apatite formation speed. Lei and coworkers also investigated the size effect of several sol-gel bioactive glass particles on the bioactivity mechanism. ${ }^{23}$ Their results showed that nanoscale BG particles with a larger specific surface area exhibited a better apatite forming ability. However, the actual composition of the samples was not measured. It is thus unclear if the effect on bioactivity was solely linked to the particles size. In a series of studies performed on binary BGs with different $\mathrm{Si} / \mathrm{Ca}$ ratios $\left(\mathrm{SiO}_{2}-\mathrm{CaO}\right.$ with a silica content in the range of $\left.50-90 \% \mathrm{~mol}\right)$, Martinez et al. ${ }^{12}$ showed that the apatite growth rate was composition-related: particles with a higher $\mathrm{CaO}$ content presented a faster calcium ions release in the SBF, inducing the formation of a higher proportion of Si-OH groups at the glass surface, thus resulting in a faster growth of the apatite layer. It can thus be seen in the Table 1 that sometimes the sample presenting the highest specific surface area is the one showing the fastest HAp growth (even though the Ca quantity is lower) and that sometimes it is the contrary. Also, it is difficult to be certain of the author's conclusions because both parameters varied simultaneously or because the composition was not actually evaluated after the synthesis. Note that as in the study of De Oliveira et $a l .^{27}$, our previous study showed that the nominal and the actual composition of BGNs differ greatly. ${ }^{28}$

Therefore, the objective of this work is to unravel the impact of calcium content upon the bioactivity of BG nanoparticles, while keeping the specific surface area unchanged. To do so, binary BGNs with different compositions have been obtained through a modification of the Stöber process. The particles morphology and composition were finely characterized in order to prove that the effects observed on their bioactive properties could only be affected to their composition. 


\begin{tabular}{|c|c|c|c|c|}
\hline Reference & $\begin{array}{c}\text { Nominal } \\
\text { composition } \\
\text { Si:Ca(:P) } \\
(\mathbf{m o l})\end{array}$ & $\begin{array}{c}\text { Effective } \\
\text { composition } \\
\text { Si:Ca(:P) } \\
(\mathbf{m o l})\end{array}$ & $\begin{array}{c}\text { Effective } \\
\text { Ca/Si molar } \\
\text { ratio }\end{array}$ & $\begin{array}{c}\text { Specific surface } \\
\text { area } \\
\left(\mathbf{m}^{2} / \mathbf{g}\right)\end{array}$ \\
\hline Martinez et al. ${ }^{12}$ & $\begin{array}{l}\mathbf{0 . 5}: \mathbf{0 . 5} \\
0.7: 0.3 \\
0.9: 0.1\end{array}$ & $?$ & $?$ & $\begin{array}{c}30 \\
126 \\
184\end{array}$ \\
\hline El-Rashidy et $a l^{26}$ & $\begin{array}{c}\mathbf{0 . 6}: \mathbf{0 . 3 6 : 0 . 0 4} \\
0.48: 0.52\end{array}$ & $\begin{array}{c}\mathbf{0 . 5 8}: \mathbf{0 . 4}: \mathbf{0 . 0 2} \\
0.94: 0.06\end{array}$ & $\begin{array}{l}\mathbf{0 . 6 9} \\
0.06\end{array}$ & $\begin{array}{l}92 \\
13\end{array}$ \\
\hline Lei et $a .^{23}$ & $\begin{array}{l}\mathbf{0 . 6}: \mathbf{0 . 3 6}: \mathbf{0 . 0 4} \\
0.6: 0.36: 0.04 \\
0.6: 0.36: 0.04\end{array}$ & $?$ & $?$ & $\begin{array}{c}86 \\
20 \\
2\end{array}$ \\
\hline Saravanapavan et al. ${ }^{11}$ & $\begin{array}{l}\mathbf{0 . 5}: \mathbf{0 . 5} \\
0.7: 0.3 \\
0.9: 0.1\end{array}$ & $?$ & $?$ & $\begin{array}{c}\mathbf{4 3} \\
136 \\
185\end{array}$ \\
\hline Oliveira et $a .^{27}$ & $\begin{array}{l}0.6: 0.38: 0.02 \\
\mathbf{0 . 6}: \mathbf{0 . 3 8}: \mathbf{0 . 0 2}\end{array}$ & $\begin{array}{l}0.57: 0.39: 0.04 \\
\mathbf{0 . 8 1}: \mathbf{0 . 1 8}: \mathbf{0 . 0 1}\end{array}$ & $\begin{array}{l}0.68 \\
0.22\end{array}$ & $\begin{array}{c}76 \\
\mathbf{5 3 3}\end{array}$ \\
\hline Li et $a l^{9}{ }^{9}$ & $\begin{array}{c}\mathbf{0 . 5 5}: \mathbf{0 . 4 1 :} \mathbf{0 . 0 4} \\
0.6: 0.36: 0.04 \\
0.8: 0.16: 0.04\end{array}$ & $?$ & $?$ & $\begin{array}{l}213 \\
289 \\
431\end{array}$ \\
\hline
\end{tabular}

Table 1. Composition and specific surface area of some samples from the literature. For each study, the sample exhibiting the fastest HAp growth is enlightened in bold.

\section{MATERIALS AND METHODS}

\section{Materials}

Tetraethyl orthosilicate (TEOS, 99\%), ammonium hydroxide solution $\left(\mathrm{NH}_{4} \mathrm{OH} 28.0 \%-30 \%\right)$ and calcium nitrate tetrahydrate $\left(\mathrm{Ca}\left(\mathrm{NO}_{3}\right)_{2} \cdot 4 \mathrm{H}_{2} \mathrm{O}\right)$ were purchased from Sigma-Aldrich. Absolute ethanol $\left(\mathrm{EtOH}_{\mathrm{abs}} 99.5 \%\right)$ was obtained from VWR Chemicals.

\section{Synthesis}

The bioactive glass nanoparticles were elaborated using a modified Stöber route optimized previously in the group. ${ }^{28}$ Two solutions were prepared separately at room temperature and left under stirring for half an hour: (i) $2.34 \mathrm{~mL}$ of $\mathrm{TEOS}+20 \mathrm{~mL} \mathrm{EtOH}$ abs and (ii) $11.7 \mathrm{~mL}$ of deionized water $+17.5 \mathrm{~mL} \mathrm{EtOH}_{\mathrm{abs}}+0.75 \mathrm{~mL}(0.14 \mathrm{M})$ concentrated $\mathrm{NH}_{4} \mathrm{OH}$. Then, the first 
solution was dropped quickly in the second one. After $\mathrm{H}$ hours of stirring, $0.49 \mathrm{~g}$ of $\mathrm{Ca}\left(\mathrm{NO}_{3}\right)_{2} \cdot 4 \mathrm{H}_{2} \mathrm{O}$ dissolved in $1 \mathrm{~mL}$ of water $(\mathrm{Ca} / \mathrm{Si}$ ratio of 0.2$)$ were dropped into the solution and left under mechanical stirring for $(24-\mathrm{H})$ hours. The obtained particles were collected by centrifugation $(6297 \mathrm{~g} / 20 \mathrm{~min})$, washed with water (3 times) in order to remove non-reacted species, dried overnight at $60^{\circ} \mathrm{C}$ and finally annealed at $650^{\circ} \mathrm{C}$ for $3 \mathrm{~h}$.

\section{Physical and chemical characterizations}

The size and size distribution of the particles were investigated by transmission electron microscopy (TEM) using a Hitachi H-7650 microscope operating at $80 \mathrm{kV}$. The sample preparation and data treatment are extensively described in ref 28.

Powder X-ray diffraction (XRD) patterns were recorded using a D2 phaser (Bruker) diffractometer in Bragg-Brentano configuration ( $\mathrm{Cu} \mathrm{K \alpha}$ anode, $\left.2 \Theta=20-40^{\circ}, \Delta \Theta=0.016\right)$.

Zeta potential measurements were performed using a Zetasizer nano apparatus (Nano-ZS, Malvern Instruments). The particles were suspended in deionized water and sonicated for $10 \mathrm{~min}$ before the measurements.

The specific surface area of BGNs was assessed by nitrogen sorption measurements conducted on a Micromeritics Tristar II PLUS sorptometer. The samples were degassed under vacuum overnight at $150^{\circ} \mathrm{C}$. The specific surface area was calculated with the Brunauer-Emmett-Teller (BET) equation, using 5 points between $0.05 \leq \mathrm{P} / \mathrm{P}^{0} \leq 0.3$.

The composition of the particles was determined using inductively coupled plasma atomic emission spectroscopy (ICP-AES, ULTIMA-C spectrometer, Horiba scientific, Jobin-Yvon). The particles were first fused at $1100^{\circ} \mathrm{C}$ in an induction furnace with $\mathrm{LiBO}_{2}$ as a flux and the resulting melt dissolved in $1 \mathrm{M} \mathrm{HNO}_{3}$. Reference materials have been prepared the same way as the unknown samples, providing high points of the calibration lines, while a pure $\mathrm{LiBO}_{2}$ solution was used as the zero. The analytical lines used for the elements are: $\mathrm{Si}(\lambda=251.611 \mathrm{~nm})$ and $\mathrm{Ca}$ $(\lambda=317.933)$.

${ }^{29}$ Si Magic Angle Spinning Nuclear Magnetic Resonance Spectroscopy (MAS NMR) spectra were acquired on a Brucker Advance300 spectrometer under a magnetic field of $7.05 \mathrm{~T}$ using a 4 $\mathrm{mm}$ probe. Experiments were performed on fine powders filled in $4 \mathrm{~mm}$ zirconia rotors spinning at $10 \mathrm{kHz}$. The recorded spectra were obtained by the sum of about 2000 scans and 1200 scans respectively for bioactive glass and pure silica (calcium free) powders. The chemical shifts were referenced to TEOS (signal located at $-82.04 \mathrm{ppm}$ of TMS, tetramethylsilane). A pulse length of $5.10 \mu \mathrm{s}$ was applied with a relaxation delay of $60 \mathrm{~s}$.

Infrared spectra were acquired by Fourier Transform Infrared Spectroscopy (FTIR, Nicolet 5700, Thermo Scientific) in transmission mode on pellets (weight ratio KBr:BG = 199:1). The spectra were collected between 1400 and $400 \mathrm{~cm}^{-1}$ (resolution of $8 \mathrm{~cm}^{-1}$ ). 
The in vitro bioactivity of BGNs was assessed according to the protocol described by Kokubo et $a l .{ }^{29}$ Briefly, the powders were soaked in Simulated Body Fluid (SBF, a solution mimicking the inorganic part of blood plasma) with a concentration of $1 \mathrm{mg} / \mathrm{mL}$ and kept in an orbital shaking incubator (N-BIOTEK, NB-205) at $37^{\circ} \mathrm{C}$ during 16h, 3 days, 7 days and 17 days. The samples were recovered by centrifugation, washed gently twice with deionized water and dried at $60^{\circ} \mathrm{C}$. Then, the powders were characterized by XRD, FTIR and TEM in order to monitor HAp formation. The SBF solution was synthesized according to Kokubo's procedure ${ }^{29}$ and used freshly prepared.

\section{Cell culture}

Human Mesenchymal Stem Cells (h-MSCs) were extracted from metaphysic cancellous bones collected during hip arthroplasty surgical procedures performed on patients. Note that before the intervention, the patients signed an authorization for the use of their bones for research purposes. Then, those bones were poured in a solution of sterile phosphate buffered saline (PBS) supplemented with $2 \%$ of heparin and transported immediately to the cell culture laboratory. After a washing step in PBS and filtration, the samples were cut in small pieces and incubated 15 min at $37^{\circ} \mathrm{C}$ with $6 \mathrm{~mL}$ of minimum essential media (MEM) and $0.2 \mathrm{~mL}$ of collagenase. Then, the samples pieces were filtrated and washed with PBS again. h-MSCs were suspended in a standard marrow cell culture medium composed of MEM supplemented with gentamycin, sodium pyruvate, vitamins, non-essential amino acids and fetal bovine serum and plated at $20 \times 10^{6}$ cells in a $25 \mathrm{~cm}^{2}$ tissue culture flasks at $37^{\circ} \mathrm{C}$ with $5 \%$ of humidified $\mathrm{CO}_{2}$ for three days. The non-adherent cells were harvested with two gentle rinses with PBS and removed. Adherent h-MSCs were fed by a weekly change of medium and expanded through one of three passages before being collected by trypsinization.

\section{In vitro cytotoxicity tests}

For the cytotoxicity tests, the BG nanoparticles have been sterilized by keeping them in an oven at $180^{\circ} \mathrm{C}$ during $2 \mathrm{~h}$.

h-MSCs seeded in a 24 -well plate $\left(5 \times 10^{4}\right.$ cells/well $)$ were exposed to sterilized bioactive glass powders with a ratio of $1 \mathrm{mg} / \mathrm{mL}$ and incubated during 1 week at $37^{\circ} \mathrm{C}$. Cells cultured in MEM seeded in wells without any powder were used as control. At the end of the incubation period, the mitochondrial activity of the cells was evaluated towards MTT (3-(4,5-dimethylthiazol-2-yl)2,5-diphenyl tetrazolium bromide) assays. Briefly, $100 \mu \mathrm{L}$ of the MTT reagent $(5 \mathrm{mg} / \mathrm{mL}$ in PBS) were added to each well. Culture plates were then incubated $3 \mathrm{~h}$ at $37^{\circ} \mathrm{C}$ with $5 \%$ of $\mathrm{CO}_{2}$. After, the content of each well was removed without touching the powders and the cells at the bottom of the well. $500 \mu \mathrm{L}$ of dimethyl sulfoxide (DMSO) were then added to each well. After 40 
min of dissolution, the optical density (OD) of each well was measured at $570 \mathrm{~nm}$ and $690 \mathrm{~nm}$ (spectrophotometer TEKAN).

\section{Statistical analysis}

All the experiments were performed in triplicate. The differences between the samples results were analyzed using the Mann-Whitney non-parametric test with the Bonferroni correction. $p$ values inferior to 0.05 were considered significant.

\section{RESULTS AND DISCUSSION}

\subsection{Characterization of the elaborated samples}

Morphology and specific surface area

In our previous study, ${ }^{28}$ a modified Stöber protocol has been established in order to synthesize bioactive glass nanoparticles (BGNs) with controlled size and composition. Based on this study, particles with similar size and different $\mathrm{Ca} / \mathrm{Si}$ molar ratios have been produced using an initial $\mathrm{Ca} / \mathrm{Si}$ molar ratio of 0.2 and a calcium salt addition time in the media (after the beginning of the sol-gel reaction) ranging from 1 to $3 \mathrm{~h}$. The Figure 1 shows the TEM micrographs of the BGNs obtained with $\mathrm{H}=1 \mathrm{~h}(\mathrm{BGNs}+1 \mathrm{~h}), 2 \mathrm{~h}(\mathrm{BGNs}+2 \mathrm{~h})$ and $3 \mathrm{~h}(\mathrm{BGNs}+3 \mathrm{~h})$. All the particles exhibit a spherical morphology. BGNs $+2 \mathrm{~h}$ and $\mathrm{BGNs}+3 \mathrm{~h}$ particles are well separated but BGNs $+1 \mathrm{~h}$ ones are partially aggregated. The mean diameters and the size distributions extracted from lognormal function fits are respectively of $156 \pm 23 \mathrm{~nm}, 179 \pm 25 \mathrm{~nm}$ and $175 \pm 21 \mathrm{~nm}$. One can note that the standard deviation is about $15 \%$ for the 3 samples which shows a narrow size dispersity of the nanoparticles as expected. It is well known that under Stöber conditions, dense and individual silica particles are obtained through successive steps which could be described as follow. Shortly after the solutions 1 and 2 mixing, primary silica particles (PSPs) start to grow through hydrolysis and condensation of TEOS. Then, the PSPs coalesce leading to the formation of secondary spherical particles. Finally, Oswald ripening promotes the homogenization of the particles size. A colloid of silica particles is obtained thanks to the high $\mathrm{pH}$ of the media which induces a net negative charge at their surface. However, the following calcium salt addition can promote aggregation and morphology inhomogeneity, as mentioned in our previous study. ${ }^{28}$ Indeed, aggregated particles are obtained when $\mathrm{Ca}\left(\mathrm{NO}_{3}\right)_{2}$ is added at $\mathrm{H} \leq 1 \mathrm{~h}$. We assume that for such an early Ca salt addition time, the silica particles are not fully formed yet. In that case, their surface is more reactive, leading to the adsorption of a large quantity of $\mathrm{Ca}^{2+}$ ions, promoting a strong electrostatic attraction destabilizing the colloid. The BGNs synthesized here show a regular morphology and a good dispersibility for $\mathrm{H}=2 \mathrm{~h}$ and $3 \mathrm{~h}$, in accordance with our previous study and zeta potential measurements $(-18 \pm 4 \mathrm{mV},-17 \pm 4 \mathrm{mV}$ and $-18 \pm 4 \mathrm{mV}$ for $\mathrm{H}=1,2$ and $3 \mathrm{~h}$ respectively). One can see that there is no significant difference between the zeta 
potential values for the 3 samples. It will thus not be a parameter to be taken into account when comparing their bioactive properties.
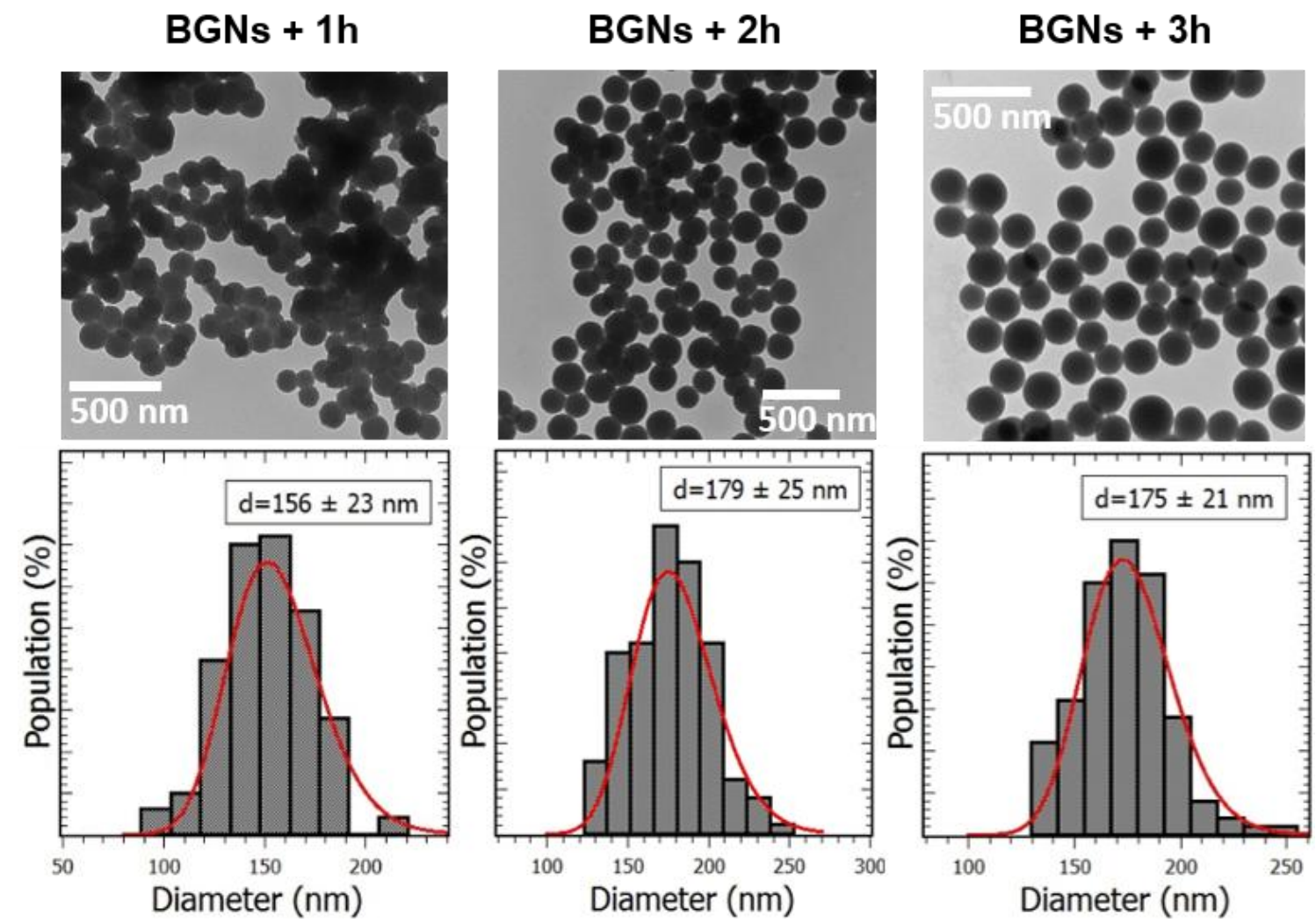

Figure 1. TEM images and size distribution histograms of BGNs+1h, BGNs+2h and BGNs+3h.

The specific surface area of the samples was measured using $\mathrm{N}_{2}$ adsoprtion-desorption technique (BET model). The isotherms are of type III, characteristic of non-porous materials according to the IUPAC classification (see Figure 2). The specific surface area of BGNs+1h, BGNs+2h and BGNs $+3 \mathrm{~h}$ are respectively of 18,20 and $19 \mathrm{~m}^{2} / \mathrm{g}$, which is significantly higher than the one of melt-derived micron-sized particles. ${ }^{30}$ Regarding the mean size of BGNs $+1 \mathrm{~h}$ particles, one could have expected a higher specific surface area value but, as they are slightly agregated, the specific surface area is in the end similar to the one of the 2 other samples. 
BGNs + 1h

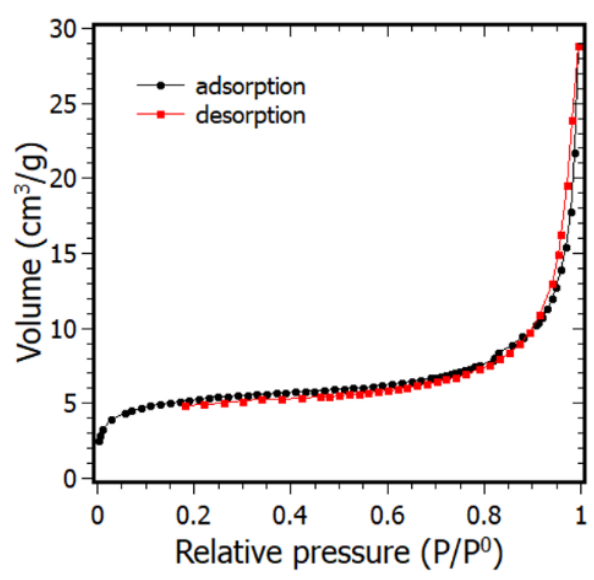

BGNs + 2h

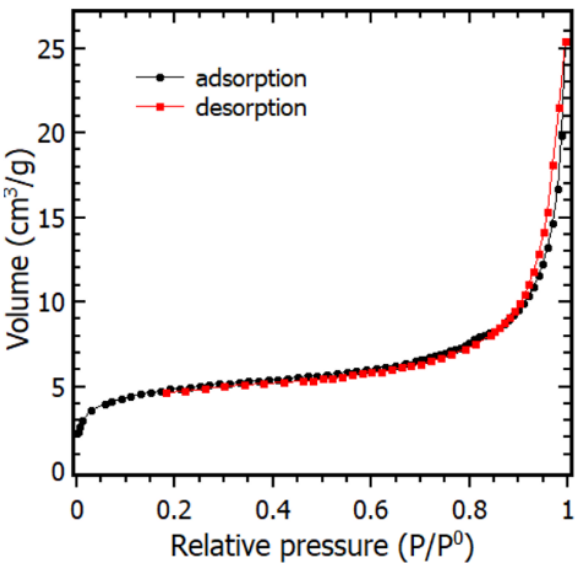

BGNs + 3h

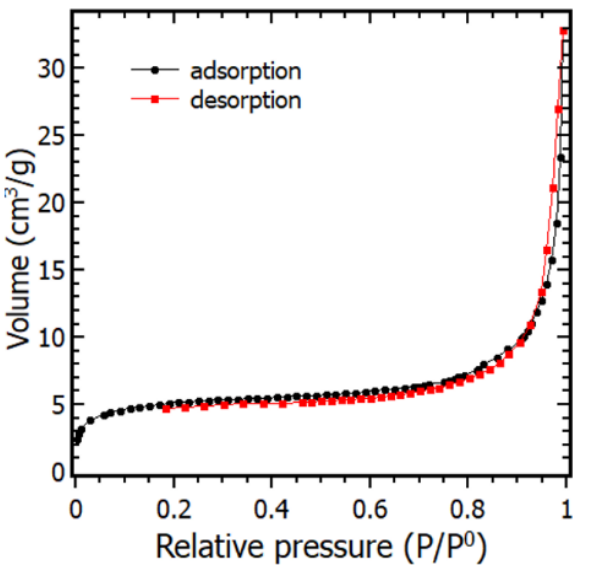

Figure 2. Adsorption-desorption isotherms of BGNs+1h, BGNs+2h and BGNs+3h.

\section{Composition}

When elaborating a binary bioactive system, one important parameter which must be carefully controlled is the final calcium / silicon ratio, as it is believed to have a strong impact on the hydroxyapatite formation rate at the glass surface. ${ }^{12}$ Since the discovery of the well-known 45S5 bioglass, the composition range for which a glass shows bioactivity has been extended thanks to the development of sol-gel process (down to $10 \% \mathrm{~mol}$ of $\mathrm{CaO}$ ). But in numerous studies, no precise measurement of the actual $\mathrm{Ca} / \mathrm{Si}$ ratio is performed, making difficult to compare the samples and conclude on the best protocol to synthesize bioactive particles. Here, the composition of BGNs has been precisely determined by ICP-AES. The final $\mathrm{Ca} / \mathrm{Si}$ molar ratio i.e. the quantity of calcium inserted inside the silica network, decreases when the time of calcium salt addition is delayed (see Table 2). At $\mathrm{H}=1 \mathrm{~h}, 88 \%$ of the calcium initially present in the media has been incorporated $(\mathrm{Ca} / \mathrm{Si}=0.182)$ and at $\mathrm{H}=2 \mathrm{~h}$ and $\mathrm{H}=3 \mathrm{~h}, 62 \%$ and $38 \%$ respectively $(\mathrm{Ca} / \mathrm{Si}=0.117$ and 0.074$)$. These results are perfectly consistent with those presented in our previous article where we showed that there was a decrease of the quantity of calcium ions inserted, from 90 to $37 \%$, when the calcium salt was added 1 to $3 \mathrm{~h}$ after the beginning of the sol-gel reaction. In our previous study, we also carried out the calcium salt addition at $\mathrm{H}>3 \mathrm{~h}$ (up to $6 \mathrm{~h}$ ) and observed that the quantity of calcium inserted in the silica network was even lower (down to $16 \%$ of incorporation), this is why $\mathrm{H}=1,2$ and $3 \mathrm{~h}$ have been selected for the present study. This deviation between the nominal and actual BGNs composition can be attributed to the washing steps (removing the non-adsorbed calcium ions). It is however important to note that the washing steps are mandatory because of the presence of unreacted precursors in the solution which could still react during the drying step and form impurities. For another part, the reduced $\mathrm{Ca}$ ion adsorption can also be linked to a decrease of negative charge density at the silica particles surface just before the calcium salt addition, as reported in our 
previous study ${ }^{28}$ Indeed, when hydrolysis and condensation are still ongoing (for $\mathrm{H} \leq 1 \mathrm{~h}$ ), many active sites might be available to interact with $\mathrm{Ca}^{2+}$ ions, whereas fewer of these sites remain available for $\mathrm{H} \geq 2 \mathrm{~h}$, leading to a lower quantity of $\mathrm{Ca}$ in the final particles.

\begin{tabular}{|c|c|c|c|c|}
\hline Samples & $\begin{array}{c}\text { Initial Ca/Si } \\
\text { molar ratio }\end{array}$ & $\mathrm{SiO}_{2}(\%$ mol $)$ & $\mathrm{CaO}(\% \mathrm{~mol})$ & $\begin{array}{c}\text { Effective Ca/Si } \\
\text { molar ratio }\end{array}$ \\
\hline BGNs+1h & 0.2 & $84.6 \pm 0.8$ & $15.4 \pm 0.1$ & $0.182 \pm 0.002$ \\
\hline BGNs+2h & 0.2 & $89.4 \pm 0.9$ & $10.6 \pm 0.1$ & $0.117 \pm 0.002$ \\
\hline BGNs+3h & 0.2 & $93.1 \pm 0.9$ & $6.9 \pm 0.1$ & $0.074 \pm 0.001$ \\
\hline
\end{tabular}

Table 2. BGNs composition determined by ICP-AES.

\section{Structure}

The decrease in $\mathrm{Ca}^{2+}$ ions quantity inserted with the calcium salt addition time can be confirmed by assessing the Si local structure by ${ }^{29} \mathrm{Si}$ solid state NMR spectroscopy. In an illustrative example, the Figure 3 shows the recorded spectra (purple) of pure silica (100Si) and BGNs+2h which were deconvoluted using 2 Gaussian functions (red and blue). Spectral deconvolution is necessary to identify the different $\mathrm{Q}^{\mathrm{n}}$ species present in the silica network, where $\mathrm{Q}$ represents the $\mathrm{SiO}_{4}$ tetrahedron units and $\mathrm{n}(0 \leq \mathrm{n} \leq 4)$ the number of bridging oxygen between neighboring silicon atoms. Here, one can notice two chemical shifts in the ranges of [-109 ppm; -112 ppm] and [-100 ppm; -102 ppm] which can be assigned to $\mathrm{Q}^{4}$ and $\mathrm{Q}^{3}$ silica units respectively. ${ }^{31}$ The relative populations evaluated for the 4 samples (100Si and BGNs $+X \mathrm{~h}, X=1,2,3)$ are listed in the Table 3 and show that the proportions of $\mathrm{Q}^{4}$ and $\mathrm{Q}^{3}$ species in BGNs powders are perfectly consistent with the amount of $\mathrm{Ca}$ inserted in the $\mathrm{SiO}_{2}$ particles. As the effective $\mathrm{Ca} / \mathrm{Si}$ ratio increases, the relative population of $\mathrm{Q}^{4}$ units decreases (and the one of $\mathrm{Q}^{3}$ units increases), meaning that the coordination number $(\mathrm{CN})$ decreases. This is consistent with the higher quantity of $\mathrm{Ca}^{2+}$ ions inserted in the particles as they act like network modifiers: the post-synthesis thermal treatment induces a disruption of the glass network due to the Si-O-Si bonds breaking by $\mathrm{Ca}^{2+}$ ions. ${ }^{25}$ Hence, non-bridging oxygens (NBOs) are created in the glass structure, resulting in the formation of $\left(\mathrm{O}-\mathrm{Si}-\mathrm{NBO}^{-}\right)$bonds whose negative charge are compensated by $\mathrm{Ca}^{2+}$ or $\mathrm{H}^{+}$ ions. ${ }^{32,33}$ Therefore, the higher the $\mathrm{Ca} / \mathrm{Si}$ ratio is, the lower the network connectivity of the glass is. 

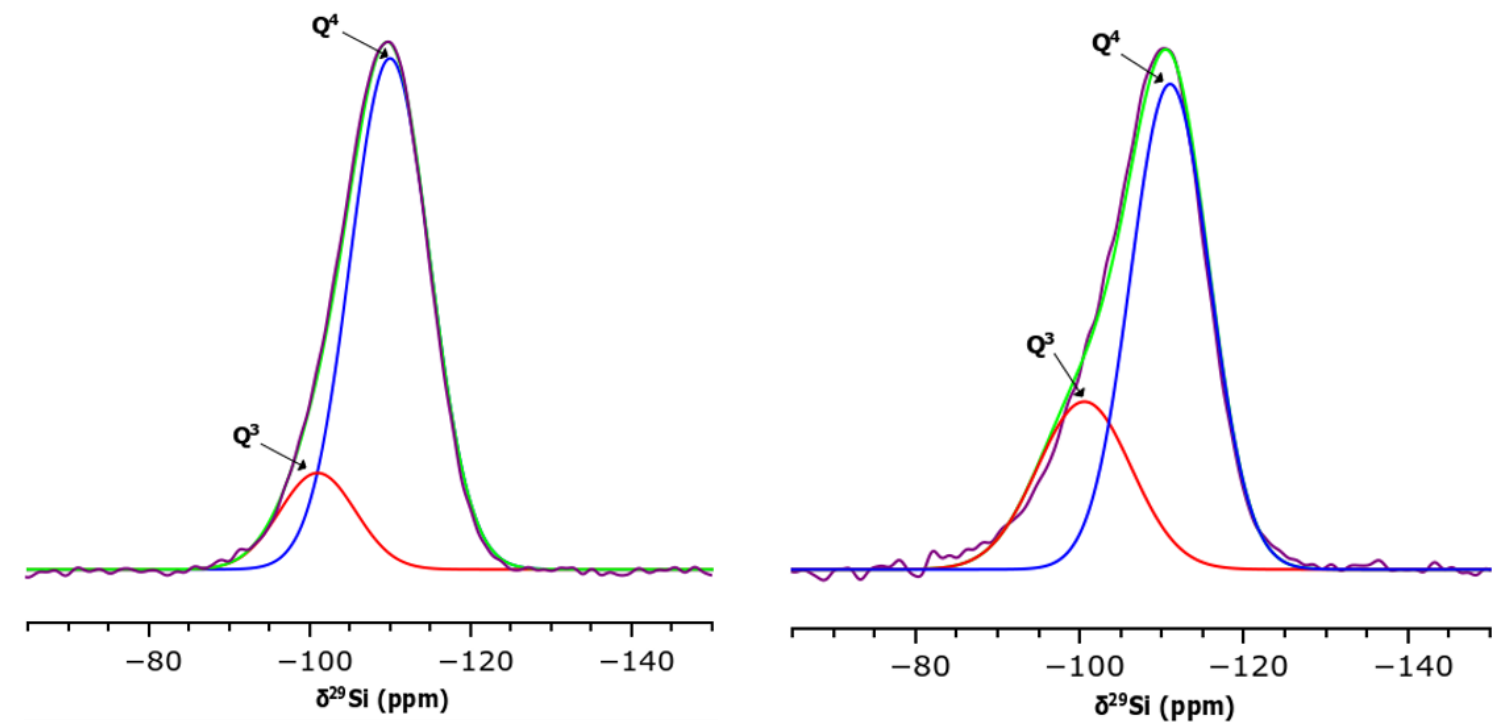

Figure 3. Experimental ${ }^{29} \mathrm{Si} \mathrm{RMN}$ spectra of $100 \mathrm{Si}$ (left) and BGNs+2h (right) fitted with Gaussian functions corresponding to $\mathrm{Q}^{4}$ units (blue) and $\mathrm{Q}^{3}$ units (red). The green curves correspond to the sum of these 2 Gaussians.

\begin{tabular}{|c|c|c|c|c|c|}
\hline \multirow{2}{*}{ Samples } & \multicolumn{2}{|c|}{$\mathrm{Q}^{4}$} & \multicolumn{2}{c|}{$\mathrm{Q}^{3}$} & \multirow{2}{*}{$\mathrm{CN}$} \\
\cline { 2 - 5 } & $\delta(\mathrm{ppm})$ & $\begin{array}{c}\text { Population } \\
(\%)\end{array}$ & $\delta(\mathrm{ppm})$ & $\begin{array}{c}\text { Population } \\
(\%)\end{array}$ & \\
\hline 100Si & $-109.85 \pm 0.08$ & $85 \pm 2$ & $-101.4 \pm 0.01$ & $15 \pm 1$ & $3.85 \pm 0.03$ \\
\hline BGNs+1h & $-111.91 \pm 0.04$ & $62 \pm 1$ & $-100.57 \pm 0.07$ & $38 \pm 2$ & $3.68 \pm 0.02$ \\
\hline BGNs+2h & $-111.02 \pm 0.01$ & $71 \pm 1$ & $-100.57 \pm 0.03$ & $29 \pm 1$ & $3.71 \pm 0.03$ \\
\hline BGNs+3h & $-110.34 \pm 0.07$ & $73 \pm 1$ & $-100.50 \pm 0.60$ & $27 \pm 1$ & $3.73 \pm 0.04$ \\
\hline
\end{tabular}

Table 3. ${ }^{29} \mathrm{Si}$ chemical shifts, relative populations of $\mathrm{Q}^{4}$ and $\mathrm{Q}^{3}$ species and coordination number (CN) of calcium free silica and BGNs samples.

The Figure 4a shows the IR spectra of the elaborated BGNs. Three main vibration modes of Si$\mathrm{O}-\mathrm{Si}$ groups can be observed in the $400-1300 \mathrm{~cm}^{-1}$ region. First, the band located at $475 \mathrm{~cm}^{-1}$ can be assigned to $\mathrm{Si}-\mathrm{O}-\mathrm{Si}$ rocking vibration. ${ }^{34,35}$ Secondly, the absorption bands respectively located around $800 \mathrm{~cm}^{-1}$ and between 1000 and $1250 \mathrm{~cm}^{-1}$ are typical of the bending and asymmetric stretching vibration of $\mathrm{Si}-\mathrm{O}-\mathrm{Si}$ bonds respectively. ${ }^{36,37}$ Additionally, a tiny peak around $875 \mathrm{~cm}^{-1}$ can be seen in the spectra of BGNs+1h and BGNs+2h. It can be attributed to the 
O-C-O stretching vibration in carbonate groups whose formation is a consequence of the carbonation process between atmospheric $\mathrm{CO}_{2}$ and the $\mathrm{Ca}^{2+}$ ions. ${ }^{38,39}$ Furthermore, it can be seen in the Figure $4 \mathrm{~b}$ that there is no sharp diffraction peaks in the XRD pattern of all the bioactive glass nanoparticles, confirming their purely amorphous nature.
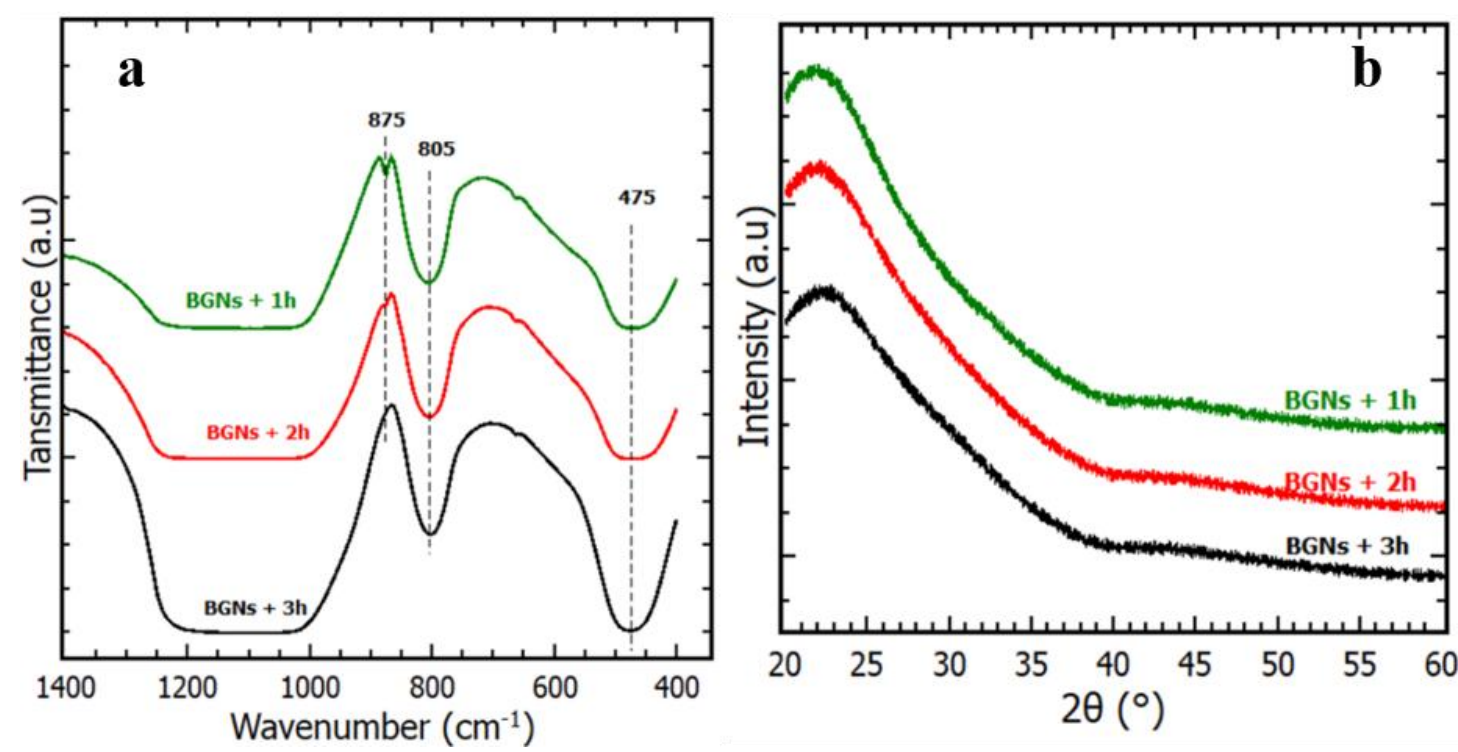

Figure 4. a) IR spectra and b) XRD patterns of BGNs.

In conclusion, the bioactive glass nanoparticles elaborated for this study have a different effective $\mathrm{Ca} / \mathrm{Si}$ ratio but their specific surface area, morphology and surface charge are similar. Hence, it is expected that if their in vitro behavior is different, it will be a consequence of their composition only.

\subsection{In vitro bioactivity}

The Figure 5 shows TEM micrographs of BGNs after immersion in SBF for 7 days. It can be seen that the particles are covered by needles identified as crystalline hydroxyapatite (HAp) by IR spectroscopy and XRD (see Figure 6). Indeed, the IR spectra exhibit two news absorption bands located at 564 and $604 \mathrm{~cm}^{-1}$ which are usually attributed to the O-P-O asymmetric bending vibration of phosphate groups in HAp. ${ }^{40}$ Also, the XRD patterns show the appearance of Bragg peaks at $2 \Theta=25.9^{\circ}, 28.4^{\circ}, 31.9^{\circ}, 33.2^{\circ}, 34.2^{\circ}, 39.7^{\circ}, 46.8^{\circ}, 49.6^{\circ}$ and $53.3^{\circ}$ which can be respectively assigned to the reticular plane families (002), (210), (211), (300), (202), (310), (222), (213) and (004) of hydroxyapatite (JCPDS 09-0432). It is thus obvious that the elaborated nanoparticles have bioactive properties. 

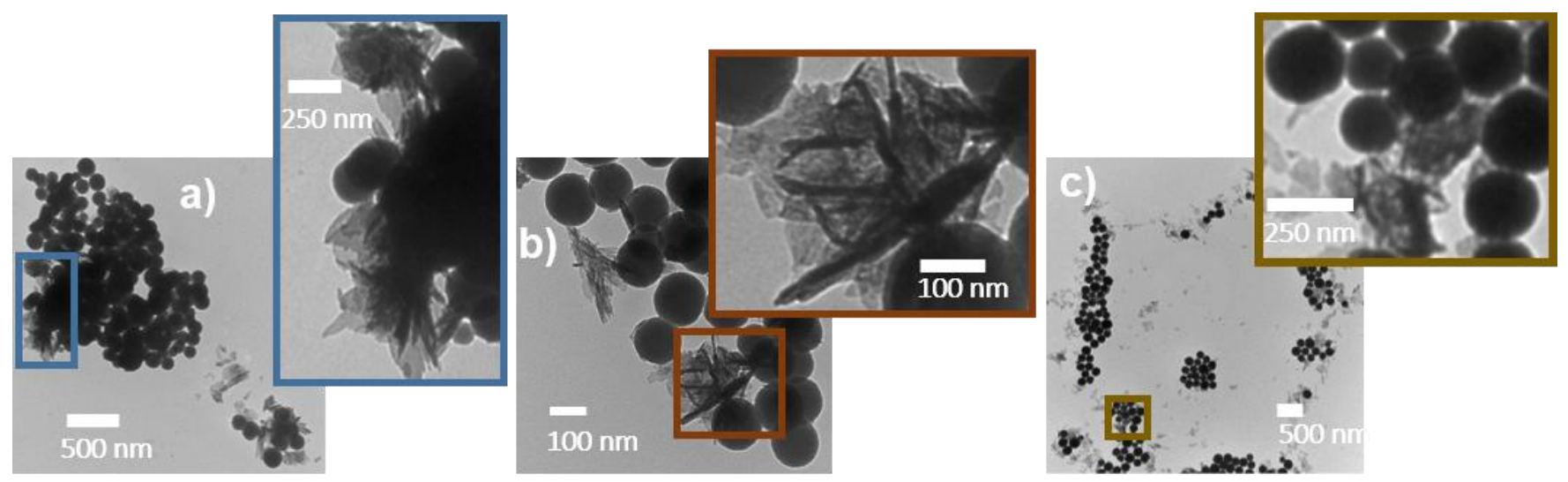

Figure 5. TEM images of a) BGNs+1h, b) BGNs+2h and c) BGNs+3h soaked in SBF for 7 days, showing needle-like crystals on their surface.
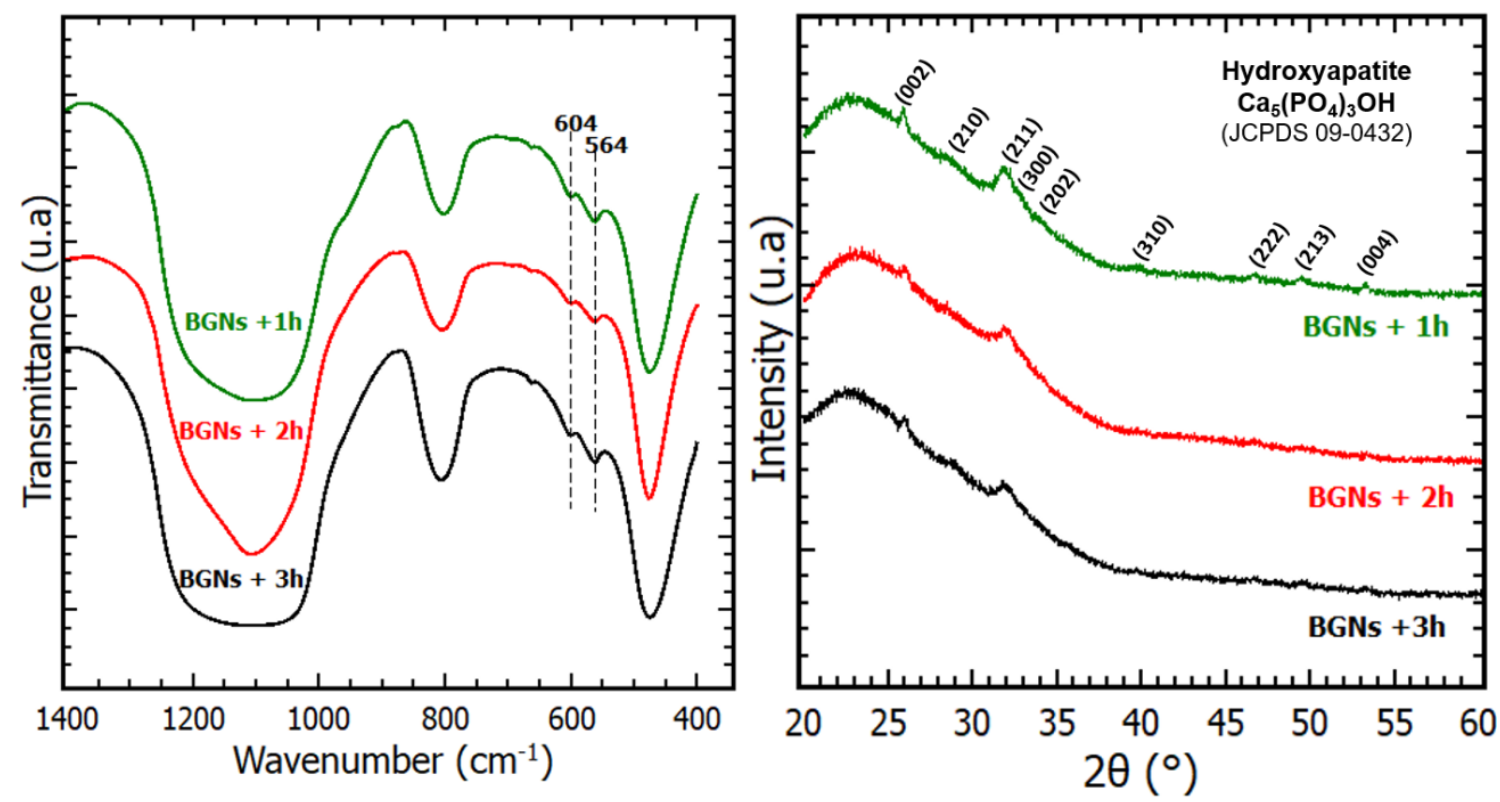

Figure 6. IR spectra (right) and XRD patterns (left) of BGNs soaked in SBF for 7 days.

In order to finely compare the relative proportion of HAp formed at the surface of the samples, the ratio " $\mathrm{r}$ " of the area under P-O-P bands (A $\mathrm{A}_{\mathrm{P}-\mathrm{O}-\mathrm{P}}$ ) over the total area $\left(\mathrm{A}_{\mathrm{T}}\right)$ under the bands located between 402 and $863 \mathrm{~cm}^{-1}$ was calculated. For each composition, five pellets were made and analyzed in order to take into account the measurement and sample preparation errors on $\mathrm{r}$ values. The results showed that the ratio $\mathrm{r}=\mathrm{A}_{\mathrm{P}-\mathrm{O}-\mathrm{P}} / \mathrm{A}_{\mathrm{T}}$ for $\mathrm{BGNs}+1 \mathrm{~h}, \mathrm{BGNs}+2 \mathrm{~h}$ and $\mathrm{BGNs}+3 \mathrm{~h}$ was respectively of $0.04 \pm 0.02,0.04 \pm 0.03$ and $0.05 \pm 0.02$. It can thus be seen that there is no significant evolution of the relative proportion of HAp when the calcium content inside the 
BGNs increases from 6.9 to $15.4 \%$. Therefore, the bioactivity of these 3 samples seems rather similar after 7 days of immersion in the SBF. However, it is important to have a closer look on HAp formation kinetics in order to have a deeper insight into the effect of the composition on the bioactivity. Indeed, as shown in Figure 7, the nucleation rate of HAp depends on the quantity of $\mathrm{Ca}$ inserted in the glass matrix. On the XRD patterns and IR spectra, one can see the peaks and vibration bands corresponding to HAp formation after 3 days of immersion for BGNs+2h and BGNs $+1 \mathrm{~h}$ samples and after 7 days for BGNs+3h. Also note that the peaks and bands are a bit sharper for the BGNs+1h sample.

In this study, the impact of the calcium content on the glass bioactivity has been investigated while keeping all the textural properties constant. We are thus certain that the discrepancies in HAp formation speed observed between the 3 bioactive glass samples are actually linked to their effective $\mathrm{Ca} / \mathrm{Si}$ ratio.

The best bioactivity (fastest mineralization) observed for the sample with the highest $\mathrm{Ca}$ content is indeed logical: an increase of the $\mathrm{Ca} / \mathrm{Si}$ molar ratio implies a less connected silica network, thus causing a faster dissolution of the glass in SBF. ${ }^{12}$ Afterwards, physico-chemical reactions (ions exchanges, silica gel network breakdown, formation of a hydrated silica layer, deposition of amorphous calcium phosphate) take place at the interface between the glass and the solution, resulting in the precipitation of apatite crystals.

Although BGNs+1h seems to be the best material for bone tissue regeneration as it promotes a quicker apatite growth, the differences with the other samples are rather small. This may be due to the fact that the BGNs composition is not the parameter which affects the most the HAp formation rate, at least in the range of composition presented in this study $(7-15 \% \mathrm{~mol}$ of $\mathrm{CaO})$. 
BGNs + 1h
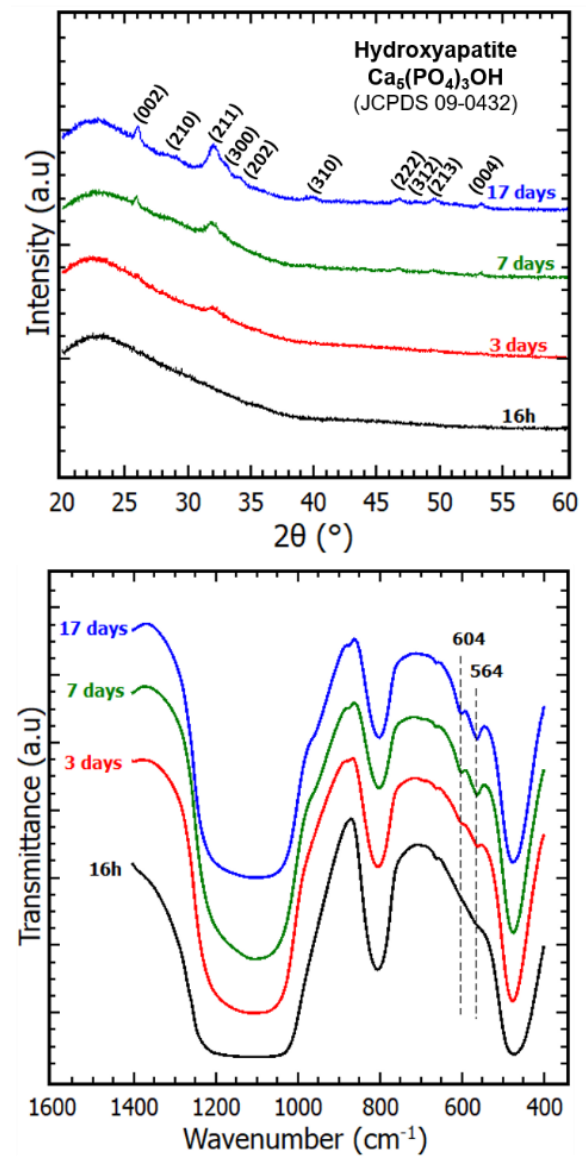

BGNs + 2h
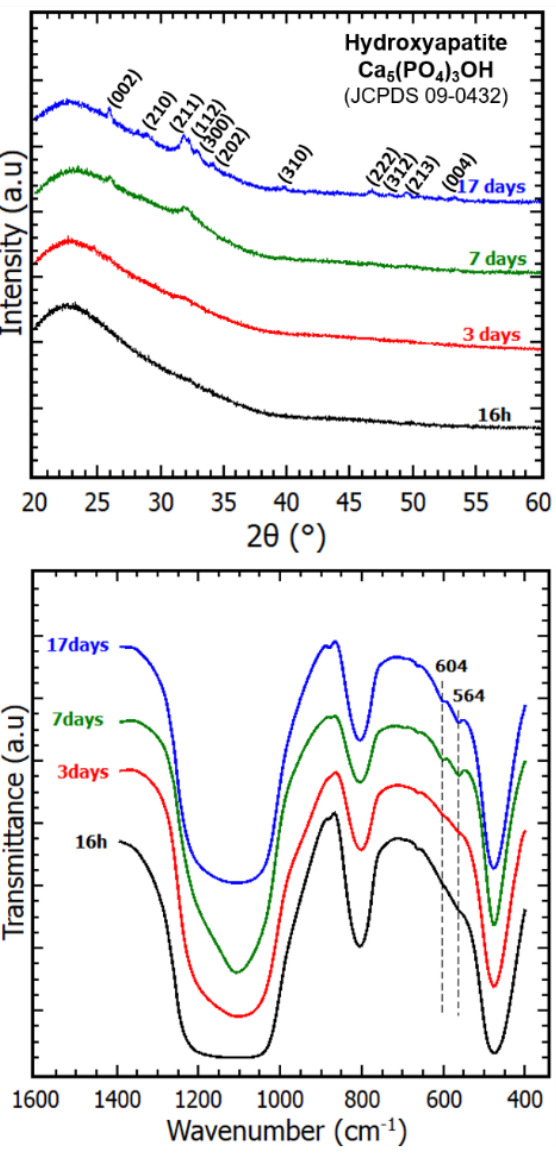

BGNs + 3h
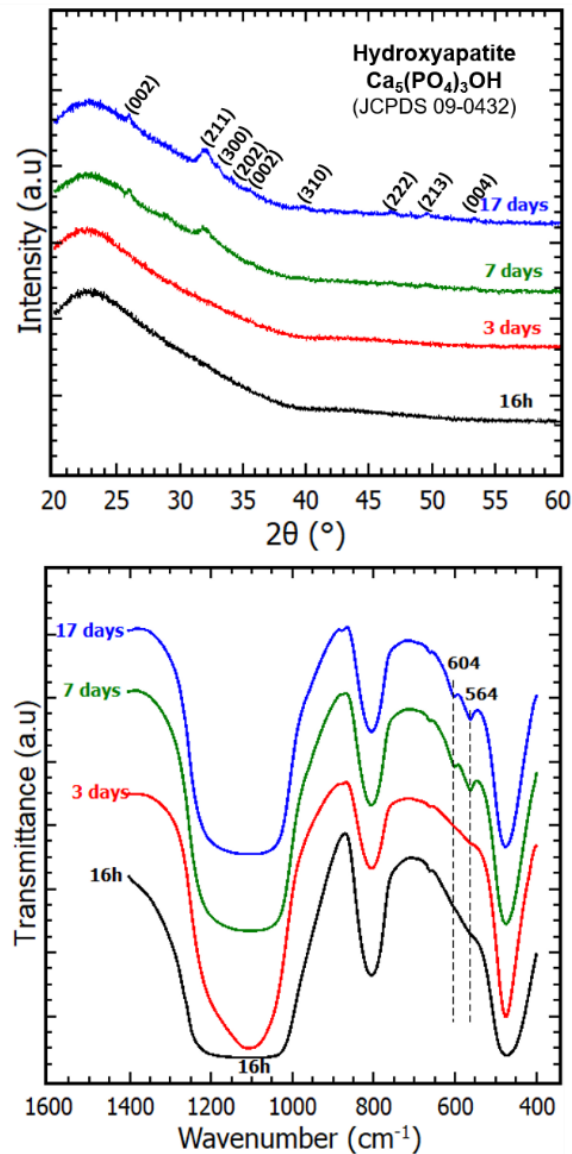

Figure 7. XRD patterns and FTIR spectra of BGNs+3h, BGNs+2h and BGNs+1h after immersion in SBF for $16 \mathrm{~h}, 3$ days, 7 days and 17 days.

\subsection{In vitro cytotoxicity tests}

The cytotoxicity evaluation of a material which is intended to be use in the human body is one of the most important requirements before further development. Consequently, the cytocompatibility assessment of the BGNs+1h was performed by evaluating the viability of hMSCs with MTT assays after exposure with the particles during 3 days and 1 week. This sample has been chosen because it showed the best bioactive property between the 3 BGNs samples in this study, as evidenced previously. As reported in the literature, a high dissolution rate of the glass and a rapid ions exchange can increase the $\mathrm{pH}$ of the cell culture medium above a critical value $(\mathrm{pH}=7.4)$ resulting in a $\mathrm{pH}$-dependent toxicity. ${ }^{41}$ Therefore, the biological studies were performed on raw powder (BGNs+1h) and on the same powder pre-treated in SBF during 1 week (SBF-BGNs+1h). 
Compared to the control, the cells viability in the presence of the bioactive glass nanoparticles (pre-treated in SBF or not) does not change significantly, as evidenced by the statistical analysis ( $p>0.05$, see Figure 8). Thus, it is obvious that the SBF-BGNs+1h and BGNs+1h samples are non-cytotoxic.

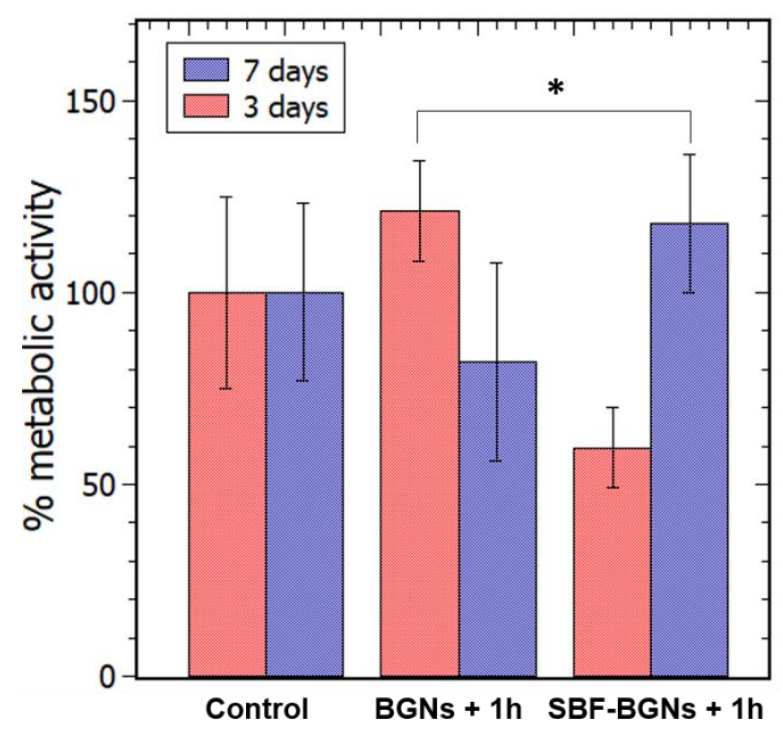

Figure 8. MTT results after exposure of BGNs+1h and SBF-BGNs+1h samples with h-MSCs cells during 3 days and 1 week. All bars represent mean $\pm \mathrm{SD}, \mathrm{n}=3, * \mathrm{p}>0.05$.

\section{CONCLUSIONS}

The calcium ions content and the specific surface area are the main parameters affecting the bioactivity mechanism of binary bioactive glasses. Up to now, the role of each parameter could not be explicitly defined as in most studies both parameters varied simultaneously. To unravel the sole effect of composition, monodispersed bioactive glass nanoparticles characterized by a similar specific surface area $\left(19 \pm 1 \mathrm{~m}^{2} / \mathrm{g}\right)$ but with different effective $\mathrm{Ca} / \mathrm{Si}$ ratio were synthesized. It was possible to vary their composition in the range of 6.9 to $15.4 \% \mathrm{~mol}$ of $\mathrm{CaO}$ by varying the calcium salt addition time in the reaction media according to a modified Stöber method developed previously in the group. In vitro bioactivity tests performed in SBF showed that increasing the effective $\mathrm{Ca} / \mathrm{Si}$ ratio induced a faster HAp growth. This effect is rather small in the composition range studied, suggesting that the bioactivity is not mainly impacted by the calcium content. Therefore, there is no need to search to increase over $10 \% \mathrm{~mol}$ calcium ions quantity for binary bioactive glasses as it will not have a significant impact on their bioactive properties. Furthermore, preliminary in vitro biocompatibility tests performed on raw and preconditioned nanoparticles $(\mathrm{CaO}=15.4 \% \mathrm{~mol})$ showed no cytotoxicity after a direct contact with 
h-MSCs up to 7 days. Based on these results, this sample is highly promising for bone tissue regeneration.

\section{CORRESPONDING AUTHOR}

* charlotte.vichery@sigma-clermont.fr, +33 473405479

\section{AUTHOR CONTRIBUTIONS}

X. Kesse, C. Vichery and J.-M. Nedelec contributed equally to the manuscript. S. Descamps and A. Jacobs respectively developed and performed the cytotoxicity tests.

\section{ACKNOWLEDGMENT}

The operation "AAP 'Nouveau Chercheur' Nanoparticules bioactives et magnétiques pour le traitement de cancer et la régénération de tissus osseux » is co-funded by the European Union as part of the Fonds Européen de Développement Régional (FEDER) and by the Conseil Regional Auvergne-Rhône-Alpes. The author wish to thank Christelle Blavignac from CICS for technical assistance (TEM measurements) and Elodie Petit for ${ }^{29} \mathrm{Si}$ NMR measurements.

\section{ABBREVIATIONS}

BET, Brunauer-Emmett-Teller; BGs, bioactive glasses; BGNs, bioactive glass nanoparticles; $\mathrm{CN}$, coordination number; DMSO, dimethyl sulfoxide; FTIR, Fourier Transform Infrared Spectroscopy; HAp, hydroxyapatite; h-MSCs, Human Mesenchymal Stem Cells; ICP-AES, inductively coupled plasma-atomic emission spectroscopy; IUPAC, International Union of Pure and Applied Chemistry; MAS NMR, Magic Angle Spinning Nuclear Magnetic Resonance Spectroscopy; MEM, minimum essential media; MTT, 3-(4,5-dimethylthiazol-2-yl)-2,5-diphenyl tetrazolium bromide; NBOs, non-bridging oxygens; OD, optical density; PBS, phosphate buffered saline; PSPs, primary silica particles; SBF, simulated body fluid; TEM, transmission electron microscopy; TEOS, tetraethyl orthosilicate; TMS, tetramethylsilane; XRD, X-ray diffraction;

\section{REFERENCES}

(1) Jones, J. R. Review of Bioactive Glass: From Hench to Hybrids. Acta Biomaterialia 2013, $9(1), 4457-4486$.

(2) Hench, L. L. The Story of Bioglass ${ }^{\circledR} . J$ Mater Sci: Mater Med 2006, 17 (11), 967-978.

(3) Bae, W.-J.; Min, K.-S.; Kim, J.-J.; Kim, J.-J.; Kim, H.-W.; Kim, E.-C. Odontogenic Responses of Human Dental Pulp Cells to Collagen/Nanobioactive Glass Nanocomposites. Dental Materials 2012, 28 (12), 1271-1279. 
(4) Sarker, B.; Hum, J.; Nazhat, S. N.; Boccaccini, A. R. Combining Collagen and Bioactive Glasses for Bone Tissue Engineering: A Review. Advanced Healthcare Materials 2015, 4 (2), 176-194.

(5) Zamet, J. s; Darbar, U. R.; Griffiths, G. s.; Bulman, J. s.; Brägger, U.; Bürgin, W.; Newman, H. N. Particulate Bioglass ${ }^{\circledR}$ as a Grafting Material in the Treatment of Periodontal Intrabony Defects. Journal of Clinical Periodontology 1997, 24 (6), 410-418.

(6) Gatti, A. M.; Simonetti, L. A.; Monari, E.; Guidi, S.; Greenspan, D. Bone Augmentation with Bioactive Glass in Three Cases of Dental Implant Placement. Journal of Biomaterials Applications 2006, 20 (4), 325-339.

(7) Zehnder, M.; Söderling, E.; Salonen, J.; Waltimo, T. Preliminary Evaluation of Bioactive Glass S53P4 as an Endodontic Medication In Vitro. Journal of Endodontics 2004, 30 (4), 220-224.

(8) Waltimo, T.; Brunner, T. J.; Vollenweider, M.; Stark, W. J.; Zehnder, M. Antimicrobial Effect of Nanometric Bioactive Glass 45S5. J Dent Res 2007, 86 (8), 754-757.

(9) Li, R.; Clark, A. E.; Hench, L. L. An Investigation of Bioactive Glass Powders by Sol-Gel Processing. J. App. Biomater. 1991, 2 (4), 231-239.

(10) Vichery, C.; Nedelec, J.-M. Bioactive Glass Nanoparticles: From Synthesis to Materials Design for Biomedical Applications. Materials 2016, 9 (4), 288.

(11) Saravanapavan, P.; Hench, L. L. Low-Temperature Synthesis, Structure, and Bioactivity of Gel-Derived Glasses in the Binary CaO-SiO2 System. Journal of Biomedical Materials Research 2001, 54 (4), 608-618.

(12) Martínez, A.; Izquierdo-Barba, I.; Vallet-Regí, M. Bioactivity of a $\mathrm{CaO}-\mathrm{SiO}_{2}$ Binary Glasses System. Chemistry of Materials 2000, 12 (10), 3080-3088.

(13) Jones, J. R.; Ehrenfried, L. M.; Hench, L. L. Optimising Bioactive Glass Scaffolds for Bone Tissue Engineering. Biomaterials 2006, 27 (7), 964-973.

(14) Sepulveda, P.; Jones, J. R.; Hench, L. L. Bioactive Sol-Gel Foams for Tissue Repair. Journal of Biomedical Materials Research 2002, 59 (2), 340-348.

(15) Christenson, E. M.; Anseth, K. S.; van den Beucken, J. J. J. P.; Chan, C. K.; Ercan, B.; Jansen, J. A.; Laurencin, C. T.; Li, W.-J.; Murugan, R.; Nair, L. S.; Ramakrishna, S.; Tuan, R. S.; Webster, T. J.; Mikos, A. G. Nanobiomaterial Applications in Orthopedics. J. Orthop. Res. 2007, 25 (1), 11-22. 
(16) Yao, C.; Perla, V.; McKenzie, J. L.; Slamovich, E. B.; Webster, T. J. Anodized Ti and Ti6A14V Possessing Nanometer Surface Features Enhances Osteoblast Adhesion. Int. J. Nanomedecine. 2007. 2 (3), 487-492.

(17) Webster, T. J.; Schadler, L. S.; Siegel, R. W.; Bizios, R. Mechanisms of Enhanced Osteoblast Adhesion on Nanophase Alumina Involve Vitronectin. Tissue Eng. 2001, 7 (3), 291-301.

(18) Fan, J. P.; Kalia, P.; Di Silvio, L.; Huang, J. In Vitro Response of Human Osteoblasts to Multi-Step Sol-Gel Derived Bioactive Glass Nanoparticles for Bone Tissue Engineering. Materials Science and Engineering: C 2014, 36, 206-214.

(19) Gong, W. Y.; Dong, Y. M.; Chen, X. F.; Karabucak, B. Nano-Sized 58S Bioactive Glass Enhances Proliferation and Osteogenic Genes Expression of Osteoblast-like Cells. Chin. J. Dent. Res. 2012, 15 (2), 145-152.

(20) Mozafari, M.; Rabiee, M.; Azami, M.; Maleknia, S. Biomimetic Formation of Apatite on the Surface of Porous Gelatin/Bioactive Glass Nanocomposite Scaffolds. Applied Surface Science 2010, 257 (5), 1740-1749.

(21) Roohani-Esfahani, S. I.; Nouri-Khorasani, S.; Lu, Z. F.; Appleyard, R. C.; Zreiqat, H. Effects of Bioactive Glass Nanoparticles on the Mechanical and Biological Behavior of Composite Coated Scaffolds. Acta Biomaterialia 2011, 7 (3), 1307-1318.

(22) Wang, C.; Shen, H.; Tian, Y.; Xie, Y.; Li, A.; Ji, L.; Niu, Z.; Wu, D.; Qiu, D. Bioactive Nanoparticle-Gelatin Composite Scaffold with Mechanical Performance Comparable to Cancellous Bones. ACS Applied Materials \& Interfaces 2014, 6 (15), 13061-13068.

(23) Lei, B.; Chen, X.; Han, X.; Zhou, J. Versatile Fabrication of Nanoscale Sol-Gel Bioactive Glass Particles for Efficient Bone Tissue Regeneration. Journal of Materials Chemistry 2012, 22 (33), 16906.

(24) Stöber, W.; Fink, A.; Bohn, E. Controlled Growth of Monodisperse Silica Spheres in the Micron Size Range. Journal of Colloid and Interface Science 1968, 26 (1), 62-69.

(25) Lin, S.; Ionescu, C.; Pike, K. J.; Smith, M. E.; Jones, J. R. Nanostructure Evolution and Calcium Distribution in Sol-Gel Derived Bioactive Glass. J. Mater. Chem. 2009, 19 (9), 1276-1282.

(26) El-Rashidy, A. A.; Waly, G.; Gad, A.; Hashem, A. A.; Balasubramanian, P.; Kaya, S.; Boccaccini, A. R.; Sami, I. Preparation and in Vitro Characterization of Silver-Doped Bioactive Glass Nanoparticles Fabricated Using a Sol-Gel Process and Modified Stöber Method. Journal of Non-Crystalline Solids 2018, 483, 26-36. 
(27) Oliveira, A. A. R. de; Souza, D. A. de; Dias, L. L. S.; Carvalho, S. M. de; Mansur, H. S.; Pereira, M. de M. Synthesis, Characterization and Cytocompatibility of Spherical Bioactive Glass Nanoparticles for Potential Hard Tissue Engineering Applications. Biomed. Mater. 2013, 8 (2), 025011.

(28) Kesse, X.; Vichery, C.; Nedelec, J.-M. Deeper Insights into a Bioactive Glass Nanoparticle Synthesis Protocol To Control Its Morphology, Dispersibility, and Composition. ACS Omega 2019, 4 (3), 5768-5775.

(29) Kokubo, T.; Kim, H.-M.; Kawashita, M. Novel Bioactive Materials with Different Mechanical Properties. Biomaterials 2003, 24 (13), 2161-2175.

(30) Sepulveda, P.; Jones, J. R.; Hench, L. L. Characterization of Melt-Derived 45S5 and SolGel-Derived 58S Bioactive Glasses. Journal of Biomedical Materials Research 2001, 58 (6), 734-740.

(31) Leonova, E.; Izquierdo-Barba, I.; Arcos, D.; López-Noriega, A.; Hedin, N.; Vallet-Regí, M.; Edén, M. Multinuclear Solid-State NMR Studies of Ordered Mesoporous Bioactive Glasses. J. Phys. Chem. C 2008, 112 (14), 5552-5562.

(32) MacKenzie, K.; Smith, M. E. Multinuclear Solid-State Nuclear Magnetic Resonance of Inorganic Materials, 1st ed.; Pergamon Press, 2002; Vol. 6.

(33) Lechert, H. G. Engelhardt Und D. Michel: High Resolution Solid State NMR of Silicates and Zeolites. John Wiley \& Sons, 1987, United States: N. p. Web.

(34) Aguiar, H.; Serra, J.; González, P.; León, B. Structural Study of Sol-Gel Silicate Glasses by IR and Raman Spectroscopies. Journal of Non-Crystalline Solids 2009, 355 (8), 475480.

(35) Román, J.; Padilla, S.; Vallet-Regí, M. Sol-Gel Glasses as Precursors of Bioactive Glass Ceramics. Chem. Mater. 2003, 15 (3), 798-806.

(36) Salinas, A. J.; Vallet-Regi, M.; Izquierdo-Barba, I. Biomimetic Apatite Deposition on Calcium Silicate Gel Glasses. Journal of Sol-Gel Science and Technology 2001, 21 (1), $13-25$.

(37) Glock, K.; Hirsch, O.; Rehak, P.; Thomas, B.; Jäger, C. Novel Opportunities for Studying the Short and Medium Range Order of Glasses by MAS NMR, 29Si Double Quantum NMR and IR Spectroscopies. Journal of Non-Crystalline Solids 1998, 232-234, 113-118.

(38) Hayashi, T.; Saito, H. Preparation of $\mathrm{CaO}-\mathrm{SiO}_{2}$ Glasses by the Gel Method. J Mater Sci 1980, $15(8), 1971-1977$. 
(39) Meiszterics, A.; Rosta, L.; Peterlik, H.; Rohonczy, J.; Kubuki, S.; Henits, P.; Sinkó, K. Structural Characterization of Gel-Derived Calcium Silicate Systems. J. Phys. Chem. A 2010, 114 (38), 10403-10411.

(40) Zheng, K.; Solodovnyk, A.; Li, W.; Goudouri, O.-M.; Stähli, C.; Nazhat, S. N.; Boccaccini, A. R. Aging Time and Temperature Effects on the Structure and Bioactivity of Gel-Derived 45S5 Glass-Ceramics. J. Am. Ceram. Soc. 2015, 98 (1), 30-38.

(41) Ciraldo, F. E.; Boccardi, E.; Melli, V.; Westhauser, F.; Boccaccini, A. R. Tackling Bioactive Glass Excessive in Vitro Bioreactivity: Preconditioning Approaches for Cell Culture Tests. Acta Biomaterialia 2018, 75, 3-10.

(42) Bellucci, D.; Cannillo, V.; Sola, A.; Chiellini, F.; Gazzarri, M.; Migone, C. Macroporous Bioglass ${ }^{\circledR}$-Derived Scaffolds for Bone Tissue Regeneration. Ceramics International 2011, 37 (5), 1575-1585. 